\title{
Defective Aquaporin-2 Trafficking in Nephrogenic Diabetes Insipidus and Correction by Chemical Chaperones
}

\author{
B.K. Tamarappoo and A.S. Verkman \\ Department of Medicine and Department of Physiology, Cardiovascular Research Institute, University of California, San Francisco, \\ California $94143-0521$
}

\begin{abstract}
Five single-point aquaporin-2 (AQP2) mutations that cause non-X-linked nephrogenic diabetes insipidus (NDI) were characterized to establish the cellular defect and to develop therapeutic strategies. In Xenopus oocytes expressing AQP2 cRNAs, single-channel water permeabilities of mutants L22V, T126M, and A147T were similar to that of wild-type AQP2, whereas R187C and C181W were nonfunctional. In $\left[{ }^{35} \mathrm{~S}\right]$ methionine pulse-chase experiments in transiently transfected $\mathrm{CHO}$ cells, half-times for AQP2 degradation were $\sim 4 \mathrm{~h}$ for wild-type AQP2 and L22V, and mildly decreased for T126M (2.7 h), C181W (2.4 h), R187C (2.0 h), and A147T (1.8 h). Immunofluorescence showed three distinct AQP2-staining patterns: plasma membrane and endosomal staining (wild-type, L22V), endoplasmic reticulum (ER) staining (T126M $>$ A147T $\sim$ R187C), or a mixed pattern of reticular and perinuclear vesicular staining. Immunoblot of fractionated vesicles confirmed primary ER localization of T126M, R187C, and A147T. To determine if the AQP2-trafficking defect is correctable, cells were incubated with the "chemical chaperone" glycerol for $48 \mathrm{~h}$. Immunoblot showed that glycerol produced a nearly complete redistribution of AQP2 (T126M, A147T, and R187C) from ER to membrane/endosome fractions. Immunofluorescence confirmed the cellular redistribution. Redistribution of AQP2 mutants was also demonstrated in transfected MDCK cells, and using the chaperones TMAO and DMSO in place of glycerol in CHO cells. Water permeability measurements indicated that functional correction was achieved. These results indicate defective mammalian cell processing of mutant AQP2 water channels in NDI, and provide evidence for pharmacological correction of the processing defect by chemical chaperones. (J. Clin. Invest. 1998. 101:2257-2267.) Key words: water transport $\bullet$ protein folding $\bullet$ glycerol $\bullet$ kidney $\bullet$ urinary concentrating
\end{abstract}

\section{Introduction}

Formation of a concentrated urine in mammals requires the stimulation of water permeability across the kidney collecting duct epithelium by the antidiuretic hormone vasopressin.

Address correspondence to Alan S. Verkman, 1246 Health Sciences East Tower, Cardiovascular Research Institute, University of California, San Francisco, San Francisco, CA 94143-0521. Phone: 415-4768530. FAX: 415-665-3847. E-mail: verkman@itsa.ucsf.edu

Received for publication 19 November 1997 and accepted in revised form 26 March 1998.

The Journal of Clinical Investigation

Volume 101, Number 10, May 1998, 2257-2267

http://www.jci.org
High collecting duct water permeability facilitates osmotically driven water transport from the tubule lumen to the hypertonic interstitium of the renal medulla. A defect in vasopressin-regulated water permeability in collecting duct results in nephrogenic diabetes insipidus (NDI) ${ }^{1}$ with inability of the kidney to generate a concentrated urine (1).

Two major forms of hereditary NDI have been identifieda more common $\mathrm{X}$-linked recessive form caused by mutations in the vasopressin V2 receptor $(1,2)$ and a rare non-X-linked form caused by mutations in the aquaporin-2 (AQP2) water channel (3-5). AQP2 is a 29-kD hydrophobic glycoprotein that functions as a water-selective transporter and belongs to a family of mammalian water channels (6). Stimulation of collecting duct water permeability by vasopressin is associated with fusion of AQP2-containing vesicles with the apical plasma membrane of collecting duct principal cells $(7,8)$. Vasopressin withdrawal is associated with endocytic retrieval of functional water channels into an apparently unique, nonacidic endosomal compartment (9). Several point mutations in the AQP2-coding sequence have been identified that are associated with human NDI (10-12). Heterologous expression of cRNAs encoding the AQP2 mutants T126M, R187C, S216P, and A147T in Xenopus oocytes suggested impaired trafficking to the plasma membrane $(10,11)$. However, the mechanism(s) by which mutant AQP2 molecules cause NDI in mammalian cells remain undefined.

There are several possible cellular mechanisms by which mutant AQP2 water channels could produce a vasopressinresistant cell with low water permeability. Mutant AQP2 protein might be absent, misprocessed and degraded rapidly, incorrectly targeted, and/or intrinsically nonfunctional. In general, as found for the mutant cystic fibrosis transmembrane conductance regulator (CFTR) in cystic fibrosis (13), one or more of these mechanisms may operate for mutant AQP2 proteins. The purpose of this study was to define the mechanism(s) by which five selected NDI-causing AQP2 mutations yield phenotypically defective target cells. Mutant AQP2 water channels were expressed in mammalian cells for analysis of protein processing and targeting, and in Xenopus oocytes for quantitative determination of intrinsic water permeability. Although some AQP2 mutants showed mild differences in intrinsic water permeability and/or protein stability, each mutant had a significant defect in protein trafficking with retention in the endoplasmic reticulum (ER). Based on recent observations that certain protein-processing defects are correctable by altered temperature and/or chemical chaperones (14-17), we

1. Abbreviations used in this paper: AQP2, aquaporin-2; CFTR, cystic fibrosis transmembrane conductance regulator; $\mathrm{CHO}$, Chinese hamster ovary; ER, endoplasmic reticulum; GFP, green fluorescent protein; MDCK, Madin-Darby canine kidney; NDI, nephrogenic diabetes insipidus; $\mathrm{P}_{\mathrm{f}}$, water permeability coefficient; TIRF, total internal reflection fluorescence; TMAO, trimethylamine oxide. 
tested whether the defective trafficking of the NDI-causing AQP2 mutations is correctable. It was found that incubation of AQP2-transfected mammalian cells with the chemical chaperone glycerol and related compounds caused a remarkable redistribution of some AQP2 mutants from ER to plasma membrane and endosomes, conferring increased cellular water permeability. The in vitro correction of defective trafficking of AQP2 mutations suggests a novel strategy for pharmacotherapy of NDI.

\section{Methods}

Construction of cDNAs encoding AQP2 mutants. Human AQP2 was isolated by reverse transcriptase-PCR using human kidney cDNA as template and primers flanking the $5^{\prime}$ and $3^{\prime}$ published sequences (18). AQP2 point mutants L22V, T126M, A147T, C181W, and R187C were generated by site-directed mutagenesis using the Altered Sites II in vitro mutagenesis system (Promega Corp., Madison, WI). Constructs were confirmed by sequence analysis. In addition, epitopetagged constructs were prepared that encoded fusion proteins consisting of the wild-type or mutant AQP2 cDNAs with 10 amino acids of the human c-Myc epitope (EQKLISEEDL) at the $\mathrm{NH}_{2}$ terminus. Wild-type and mutated cDNAs were subcloned in pCDNA3 plasmid (Invitrogen, Carlsbad, CA) for transfection in mammalian cells and in pSP64T (19) for RNA transcription and expression in Xenopus oocytes.

Cell transfection. Chinese hamster ovary ( $\mathrm{CHO})-\mathrm{K} 1$ cells were grown in Hams F-12 medium containing 5\% fetal bovine serum, 100 $\mathrm{U} / \mathrm{ml}$ penicillin, and $100 \mathrm{mg} / \mathrm{ml}$ streptomycin at $37^{\circ} \mathrm{C}$ in $5 \% \mathrm{CO}_{2}$ and 95\% air. Madin-Darby canine kidney (MDCK) cells were grown in DME H-21 containing 10\% fetal bovine serum under identical conditions. For immunostaining, cells were plated at a density of $10^{4}$ per 3.8 $\mathrm{cm}^{2}$ and transfected with $0.5 \mu \mathrm{g}$ of cDNA in the presence of $3 \mu \mathrm{g}$ of lipofectamine. For MDCK cells, $10^{7}$ cells were transfected by electroporation with $30 \mu \mathrm{g}$ of plasmid DNA. In some studies, growth medium was replaced with medium containing $1 \mathrm{M}$ glycerol, $100 \mathrm{mM}$ trimethylamine oxide (TMAO), or $2 \%$ DMSO at $4 \mathrm{~h}$ after transfection. For immunoprecipitation, cells were plated at a density of $5 \times$ $10^{4}$ cells per well, and transfected with $1 \mu \mathrm{g}$ of cDNA and $6 \mu \mathrm{g}$ of lipofectamine per well.

Oocyte water permeability measurements. Complementary RNA was transcribed in vitro using SP6 RNA polymerase and $4 \mu \mathrm{g}$ of plasmid DNA at $37^{\circ} \mathrm{C}$ for $2 \mathrm{~h}$ in the presence of diguanosine triphosphate (Pharmacia Biotech., Piscataway, NJ) for capping. cRNA was purified after DNAse digestion by phenol-chloroform extraction and ethanol precipitation. Stage V and VI oocytes from Xenopus laevis were isolated, defolliculated, and microinjected with $0.05 \mu \mathrm{l}$ of water or cRNA suspensions $(5 \mathrm{ng} / \mu \mathrm{l})$. Oocytes were incubated at $18^{\circ} \mathrm{C}$ for $24 \mathrm{~h}$ and osmotic water permeability $\left(\mathrm{P}_{\mathrm{f}}\right)$ was measured from the time course of oocyte swelling at $10^{\circ} \mathrm{C}$ in response to a fivefold dilution of the extracellular Barth's buffer with distilled water (19).

Immunofluorescence. Transfected $\mathrm{CHO}$ cells grown on glass coverslips were fixed in PBS containing 3\% paraformaldehyde and then permeabilized with $0.1 \%$ Triton X-100, or first permeabilized with $0.05 \%$ saponin before fixation. Cells were incubated with polyclonal rabbit AQP2 antiserum (1:500, raised against 30 amino acids of the $\mathrm{COOH}$-terminus), or a mouse monoclonal antibody against the c-Myc epitope (20), in PBS containing $5 \mathrm{mg} / \mathrm{ml} \mathrm{BSA}$ for $1 \mathrm{~h}$ at $37^{\circ} \mathrm{C}$. For double labeling, cells were fixed and permeabilized in ice-cold methanol for $10 \mathrm{~min}$ at $-20^{\circ} \mathrm{C}$. Cells were incubated with a rat monoclonal antibody against Grp94 (provided by W.J. Welch, University of California, San Francisco, CA) in PBS containing $5 \mathrm{mg} / \mathrm{ml}$ BSA for $1 \mathrm{~h}$ at $37^{\circ} \mathrm{C}$ followed by incubation with AQP2 antiserum. Cells were rinsed in PBS and incubated in TRITC or FITC-labeled anti-rabbit antibody, FITC-labeled anti-rat antibody, or FITC-labeled anti-mouse antibody (1:60) for $1 \mathrm{~h}$. Cells were rinsed in PBS, coverslips were mounted with a drop of DABCO, and fluorescence images were photographed using a Nikon oil immersion $\times 100$ objective (numerical aperture 1.4) in the wide-field mode using Kodak T-Max 400 film push-processed to 1600 ASA. Confocal images were obtained using $\times 60$ oil immersion objective (numerical aperture 1.4) (Nikon Inc., Melville, NY) and a K2-Bio Nipkow wheel confocal microscope (Technical Instruments, San Francisco, CA). Images were photographed using a cooled CCD camera (Photometrics Ltd.).

$\left[{ }^{35}\right.$ S $]$ metabolic labeling and immunoprecipitation. Metabolic labeling and immunoprecipitation were carried out at $40 \mathrm{~h}$ after transfection when cells were $\sim 80 \%$ confluent. Cells were incubated in cysteine and methionine-free DME H-21 medium for $30 \mathrm{~min}$ at $37^{\circ} \mathrm{C}$, and then the medium was supplemented with $\left[{ }^{35} \mathrm{~S}\right]$ methionine/ cysteine $(75 \mu \mathrm{Ci} / \mathrm{ml}$; Dupont-NEN, Boston, MA) for $30 \mathrm{~min}$ (pulse labeling). Cells were then washed in medium containing $5 \mathrm{mM}$ nonradioactive methionine and cysteine, and placed in the methionine-containing medium (chase). At specified times, cells were washed in hypotonic buffer ( $25 \mathrm{mM}$ sucrose, $1 \mathrm{mM}$ Hepes, $1 \mathrm{mM}$ EDTA, pH 7.4), and homogenized by five passages through a 27 -gauge needle in $250 \mathrm{mM}$ sucrose, $10 \mathrm{mM}$ Hepes, $1 \mathrm{mM}$ EDTA, $20 \mu \mathrm{g} / \mathrm{ml} \mathrm{PMSF}, 1 \mu \mathrm{g} / \mathrm{ml}$ leupeptin, and $1 \mu \mathrm{g} / \mathrm{ml}$ pepstatin, $\mathrm{pH}$ 7.4. After pelleting debris, nuclei and mitochondria $(500 \mathrm{~g}, 10 \mathrm{~min})$, a postnuclear pellet was obtained by centrifugation of the supernatant $(100,000 \mathrm{~g}, 45 \mathrm{~min})$. The membrane pellet was solubilized PBS containing $100 \mathrm{mM} \beta$-octylglucoside and incubated with protein A-Sepharose CL-4B beads (Pharmacia Biotech.) for 1 hour at $4^{\circ} \mathrm{C}$. The beads were pelleted $(100 \mathrm{~g}, 1$ min), and the supernatant was incubated with primary antibody (AQP2 or c-Myc) bound to protein A-Sepharose CL-4B for $4 \mathrm{~h}$ at $4^{\circ} \mathrm{C}$. Beads were pelleted $(100 \mathrm{~g}, 1 \mathrm{~min})$ and washed four times in RIPA buffer (PBS containing 1\% Triton X-100, 1\% deoxycholate, $0.1 \%$ SDS). Proteins were released from the beads by incubation with $30 \mu \mathrm{l}$ of Laemmli sample buffer, resolved on a $12 \%$ SDS-polyacrylamide gel, and subjected to fluorography and autoradiography. Band intensities were quantified by densitometry and normalized to the intensity of a $46-\mathrm{kD}$ nonspecific protein.

Metabolic labeling of oocytes was performed by incubating groups of 10 oocytes for $24 \mathrm{~h}$ at $18^{\circ} \mathrm{C}$ in $100 \mu \mathrm{l}$ of Barth's buffer containing $50 \mu \mathrm{Ci}\left[{ }^{35} \mathrm{~S}\right]$ methionine (Dupont-NEN). Oocytes were washed three times in ice-cold Barth's buffer and plasma membrane complexes were peeled from the surface of the oocytes with forceps (21). Membranes were disrupted in $1 \mathrm{ml}$ of homogenization buffer $(7.5 \mathrm{mM}$ $\mathrm{Na}_{2} \mathrm{HPO}_{4}, 1 \mathrm{mM}$ EDTA, $20 \mu \mathrm{g} / \mathrm{ml}$ PMSF, $1 \mu \mathrm{g} / \mathrm{ml}$ pepstatin A, $1 \mu \mathrm{g} / \mathrm{ml}$ leupeptin, $\mathrm{pH} 7.4$ ), debris was pelleted $(750 \mathrm{~g}, 5 \mathrm{~min})$, and membranes were pelleted $(16,000 \mathrm{~g}, 30 \mathrm{~min})$. Membrane pellets were solubilized in PBS containing $100 \mathrm{mM} \beta$-octylglucoside, and immunoprecipitation was performed as described above.

Subcellular fractionation. As described by Balch et al. (22), $\mathrm{CHO}$ cells (control or transfected) grown on 10-cm plates were washed twice with ice-cold PBS, removed using a rubber cell scraper, and pelleted in PBS $(100 \mathrm{~g}, 10 \mathrm{~min})$. Cells were resuspended in homogenization buffer ( $250 \mathrm{mM}$ sucrose, $3 \mathrm{mM}$ imidazole, $1 \mathrm{mM}$ EDTA, $20 \mu \mathrm{g} / \mathrm{ml}$ PMSF, $1 \mu \mathrm{g} / \mathrm{ml}$ pepstatin A, $1 \mu \mathrm{g} / \mathrm{ml}$ leupeptin, $\mathrm{pH}$ 7.4), pelleted at $5,000 \mathrm{~g}$, resuspended in $0.5 \mathrm{ml}$ homogenization buffer, and homogenized by five passages through a 27 -gauge needle. A postnuclear supernatant was mixed with an equal volume of $2.3 \mathrm{M}$ sucrose, $3 \mathrm{mM}$ imidazole, $\mathrm{pH} 7.4$, to obtain a 1.4-M sucrose fraction. The sucrose density gradient consisted of: $0.25 \mathrm{ml}$ of $2.0 \mathrm{M}$ sucrose, $0.5 \mathrm{ml}$ of $1.6 \mathrm{M}$ sucrose, $1 \mathrm{ml}$ of $1.4 \mathrm{M}$ sucrose, $1.5 \mathrm{ml}$ of $1.2 \mathrm{M}$ sucrose, and $1 \mathrm{ml}$ of $0.8 \mathrm{M}$ sucrose. The gradients were centrifuged $(25,000 \mathrm{~g}, 2.5 \mathrm{~h})$ and $0.5-\mathrm{ml}$ fractions were collected. Each fraction was mixed with $4.5 \mathrm{ml}$ of resuspension buffer ( $3 \mathrm{mM}$ imidazole, $2 \mathrm{mM}$ EDTA, $20 \mu \mathrm{g} / \mathrm{ml}$ PMSF, $1 \mu \mathrm{g} / \mathrm{ml}$ pepstatin A, $1 \mu \mathrm{g} / \mathrm{ml}$ leupeptin, $\mathrm{pH} 7.4$ ), and membranes were pelleted $(100,000 \mathrm{~g}, 30 \mathrm{~min})$ and resuspended in a minimal volume of resuspension buffer. Protein concentrations were determined using the BCA colorimetric assay (Pierce, Rockford, IL).

Immunoblot analysis. Equal amounts of protein $(2.5 \mu \mathrm{g})$ from each fraction were resolved on a $12 \%$ SDS-polyacrylamide gel and electroblotted to a nitrocellulose membrane. Membranes were 
blocked with $5 \%$ nonfat dry milk in $10 \mathrm{mM}$ Tris, $150 \mathrm{mM} \mathrm{NaCl}, \mathrm{pH}$ 7.4 (TBS) for $2 \mathrm{~h}$, followed by a 1-h incubation in AQP2 polyclonal antibody raised against a $\mathrm{COOH}$ terminus peptide (1:500), c-Myc monoclonal antibody (1:300), calnexin antibody (1:300, polyclonal antibody provided by W.J. Welch), or alkaline phosphatase monoclonal antibody (Sigma Chemical Co., St. Louis, MO). Membranes were washed in TBS containing $0.05 \%$ Tween and incubated with horseradish peroxidase (HRP)-conjugated goat anti-rabbit IgG. Bands were visualized by enhanced chemiluminescence (Amersham Corp., Arlington Heights, IL).

Water permeability in transfected cells. A total internal reflection fluorescence (TIRF) method (23) was adapted to measure plasma membrane osmotic water permeability in intact cells. CHO cells were cotransfected with $0.5 \mu \mathrm{g}$ of plasmid encoding wild-type or mutant AQP2 together with $0.25 \mu \mathrm{g}$ of plasmid pEGFP-N (Clontech Labs., Palo Alto, CA), which results in cytoplasmic expression of green fluorescent protein (GFP). The GFP functioned as a volume marker in AQP2-expressing cells. To measure water permeability, the cells grown on coverslips were mounted in a laminar flow perfusion chamber to permit fluid exchange in $\sim 1 \mathrm{~s}$. Osmotic water permeability was determined from time course of cell volume in response to exchange between isosmolar PBS (300 mosM) and hyposmolar PBS diluted 1:1 with water (150 mosM). Relative cell volume was deduced from the GFP fluorescence signal with TIRF illumination. The optical system consisted of a He-Cd laser, TIRF prism, inverted microscope, and photomultiplier detector, as described in detail previously (23). Measurements were generally made on groups of 5-10 transfected cells in a microscope field viewed with a $\times 40$ oil immersion objective (numerical aperture 1.3).

\section{Results}

Wild-type human AQP2 and five selected single-point AQP2 mutants causing NDI were characterized in terms of their intrinsic water permeability, protein stability in mammalian cells, and protein processing in mammalian cells. Complementary RNAs encoding each AQP2 protein were expressed in Xenopus oocytes for determination of water permeability. Intrinsic (per channel) water permeability was estimated from the ratio of oocyte water permeability to the amount of plasma membrane AQP2. Fig. $1 A$ shows representative oocyte swelling curves for each of the AQP2 proteins and Fig. $1 B$ summarizes averaged water permeability coefficients, $\mathrm{P}_{\mathrm{f}}$. Wild-type AQP2 cRNA conferred an increased water permeability when compared to water-injected control oocytes. Oocytes injected with cRNA encoding AQP2 mutants L22V, T126M, and A147T had a lesser, though significant increase in water permeability. Fig. $1 C$ shows a representative autoradiogram of AQP2 after immunoprecipitation of microdissected plasma membranes. For equal quantities $(2.5 \mathrm{ng})$ of microinjected cRNA, plasma membrane expression was strongest for wildtype AQP2 and L22V, followed by T126M, A147T, and $\mathrm{R} 187 \mathrm{C}$, with no detectable expression of C181W. A single 29-kD band was seen in oocytes expressing wild-type AQP2 and L22V. For T126M, A147T, and R187C, there was in addition a $32-\mathrm{kD}$ band, which represents a core glycosylated form of the protein $(10,11)$. In previous studies this band in oocytes was attributed to contamination of the plasma membrane fraction by ER membranes (10). However, it is more likely to represent a misfolded form of AQP2 that has escaped ER retention and has failed to undergo the processing of core sugars in a post-ER compartment (24). The reduced plasma membrane expression of T126M, A147T, and R187C may result from ER retention or decreased stability of the mutant protein.

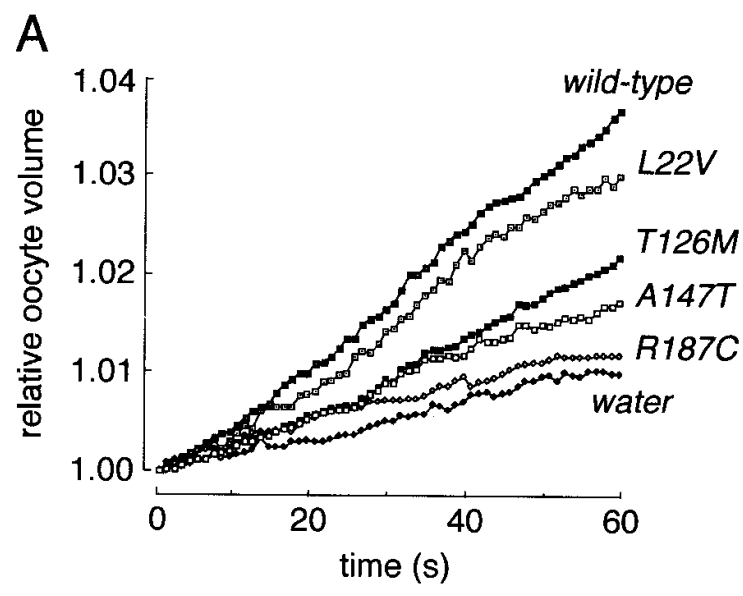

B

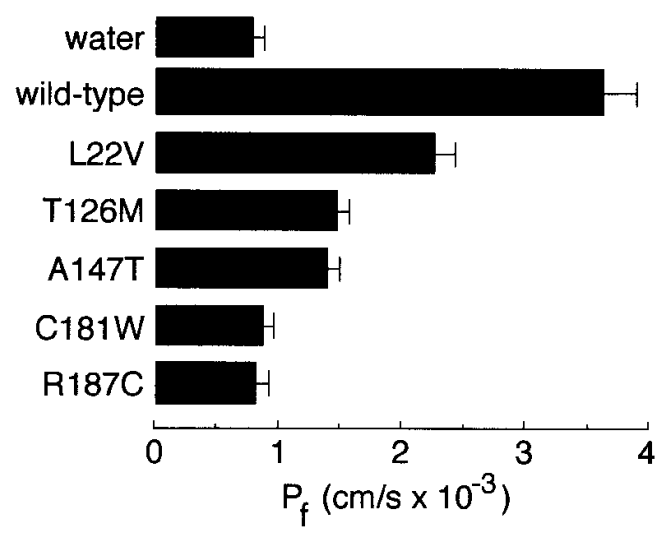

C

$\mathrm{kD}$

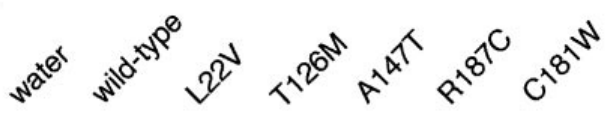

$33-$

$29-$ AQP2

$20-$

Figure 1. Water permeability of wild-type and mutant AQP2 proteins. Xenopus oocytes were microinjected with water or $2.5 \mathrm{ng}$ of indicated cRNAs and incubated at $18^{\circ} \mathrm{C}$ for $24 \mathrm{~h}$. Osmotic water permeability $\left(\mathrm{P}_{\mathrm{f}}\right)$ was measured at $10^{\circ} \mathrm{C}$. $(A)$ Representative oocyte swelling curve showing the time course of relative oocyte volume measured by oocyte swelling after a fivefold dilution of the extracellular medium with distilled water. $(B)$ Averaged $\mathrm{P}_{\mathrm{f}}$ values (mean \pm SEM, $n=10$ ). (C) Immunoprecipitation of $\left[{ }^{35} \mathrm{~S}\right]$ methionine labeled AQP2 from microdissected oocyte plasma membranes with a mouse monoclonal antibody to the c-Myc epitope at the $\mathrm{NH}_{2}$ terminus.

From the $\mathrm{P}_{\mathrm{f}}$ and plasma membrane expression data, relative single channel water permeabilities were: 1.0 (wild-type AQP2), 1.09 \pm 0.1 (L22V), 1.14 \pm 0.1 (T126M), 1.18 \pm 0.1 (A147T), and 0.0 (R187C). Although the exact permeability values should be viewed cautiously because of uncertainties in plasma 

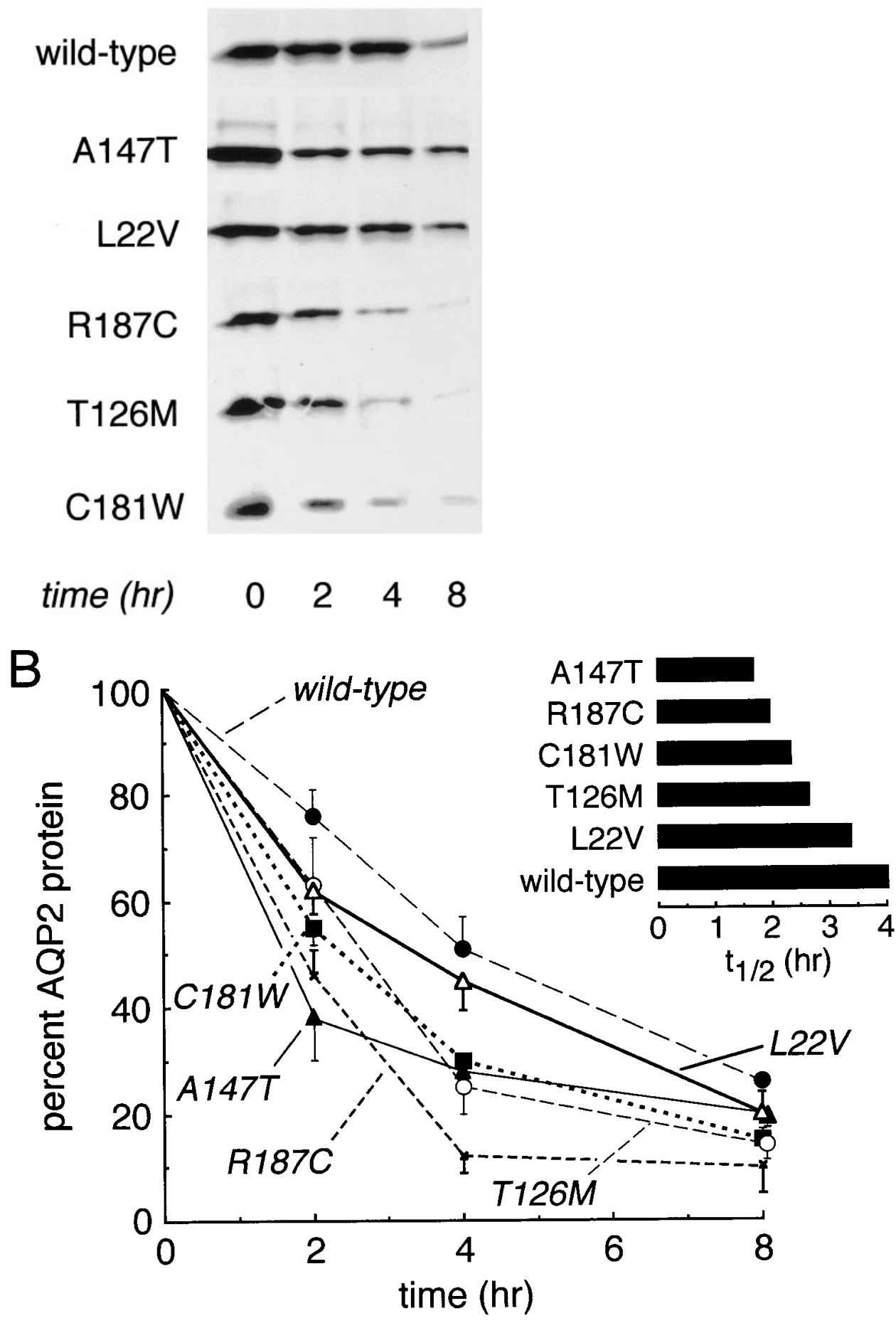

Figure 2. AQP2 protein stability in mammalian cells. $\mathrm{CHO}$ cells were transiently transfected with AQP2, cells were labeled for $30 \mathrm{~min}$ with $\left[{ }^{35} \mathrm{~S}\right]$ methionine/cysteine (pulse), and then incubated in medium containing nonradioactive methionine. AQP2 was immunoprecipitated from cell membranes. ( $A$ ) Representative autoradiograms of immunoprecipitated proteins at $0,2,4$, and $8 \mathrm{~h}$ of chase. $(B)$ Averaged kinetics of protein degradation (mean \pm SEM) from three independent experiments.

membrane dissection and band integration, these results suggest that decreased intrinsic water permeability is not the NDIcausing defect for L22V, T126M, and A147T. In AQP1, mutations of amino acids close to the conserved NPA boxes have been shown to result in the loss of water permeability (25). The R187C mutation is near the second NPA box in the extracellular loop of AQP2 and the protein is not water permeable. Although the intrinsic water permeabilitiy of $\mathrm{C} 181 \mathrm{~W}$ could not be measured because it was not expressed at the oocyte plasma membrane, the proximity of the mutation to the second NPA box predicts that it also would be nonfunctional.

AQP2 protein stability was determined in transiently transfected $\mathrm{CHO}$ cells by AQP2 immunoprecipitation at various chase times after $\left[{ }^{35} \mathrm{~S}\right]$ methionine pulse-labeling. The representative autoradiograms in Fig. $2 \mathrm{~A}$ reveal decreasing amounts of $\left[{ }^{35}\right.$ S]labeled AQP2 proteins over time. The degradation kinetics of L22V and T126M were qualitatively similar to that of wild-type AQP2, with accelerated degradation for A147T, 
C181W, and R187C. Fig. 2 B summarizes the time course of $\left.{ }^{35} \mathrm{~S}\right]$-labeled AQP2 protein (relative to that at zero time) determined by quantitative densitometry. The A147T mutant was the least stable with significantly accelerated degradation during the first $2 \mathrm{~h}$. R187C and T126M exhibited a more gradual decrease over the first $4 \mathrm{~h}$. In oocytes, accelerated degradation of A147T was observed, but T126M and R187C were relatively stable $(10,11)$. Although some of the AQP2 mutants exhibit mildly accelerated degradation, it is unlikely that decreased protein stability alone is the defect causing NDI.

Immunofluorescence was done to determine the intracellular location of AQP2 in transfected CHO cells. Three staining patterns were seen: a plasma membrane and endosome pattern for wild-type AQP2 (Fig. $3 A$ ), and both an ER-like reticular pattern for T126M and R187C (3,B and $C)$, and a mixed pattern comprised of perinuclear vesicular staining $(3, D$ and
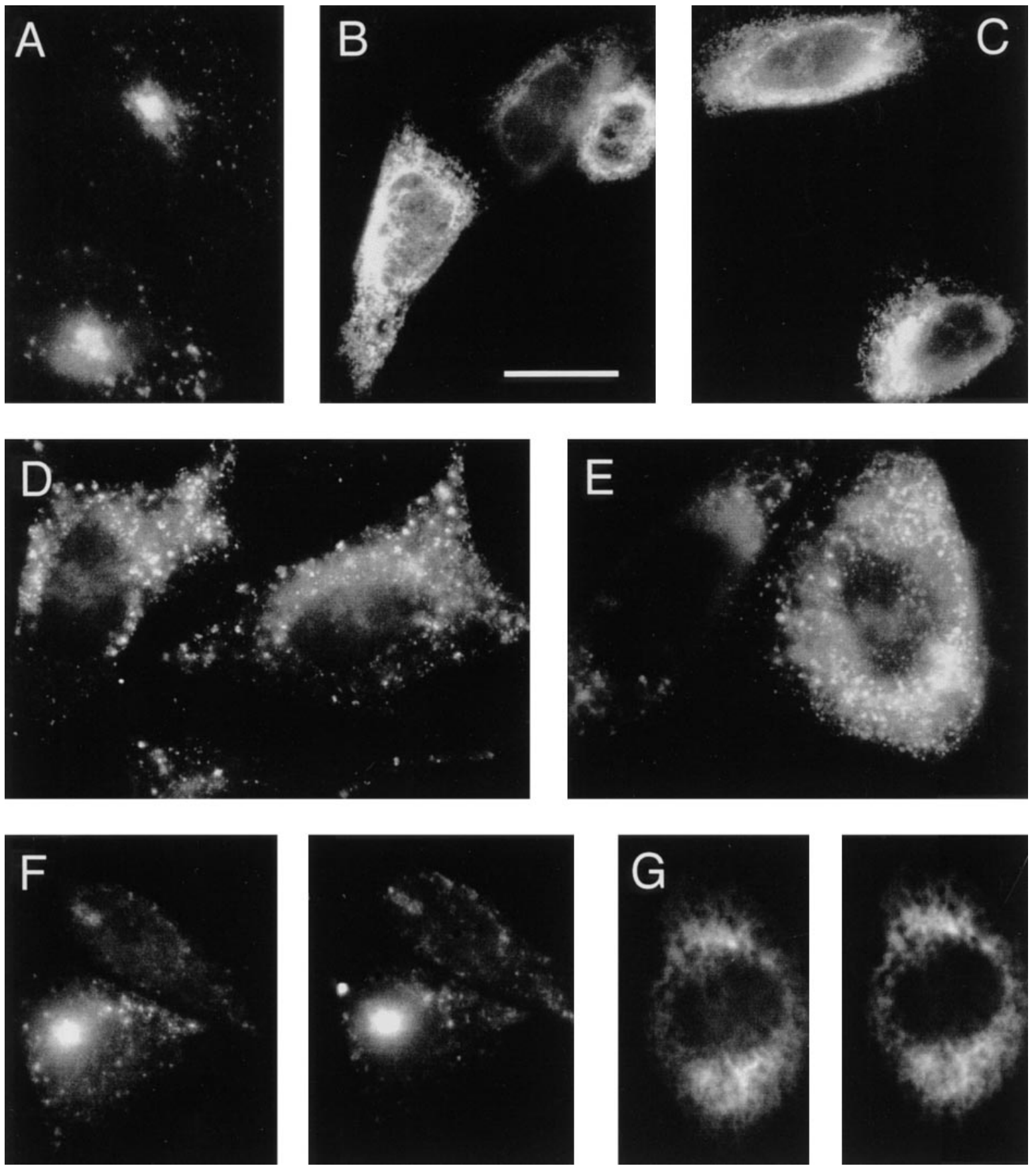

Figure 3. Intracellular localization of AQP2 protein by immunofluorescence. Panel of representative cells expressing wild-type AQP2 and each mutant stained with AQP2 antibody. (A) Wild-type AQP2. (B) T126M. (C) R187C. $(D)$ T126M. (E) R187C. (F) Colocalization of wild-type AQP2 (left) and rhodamine transferrin (right) to early and recycling endosomes by confocal microscopy. $(G)$ Colocalization of AQP2-T126M (left) and Grp94 (antibody-stained, right) to the ER. Bar, $20 \mu \mathrm{m}$. 
$E)$. The localization of A147T was also heterogeneous with cells showing reticular staining or a mixed pattern (not shown). The localization of wild-type AQP2 to endosomes was confirmed by comparison with that of rhodamine transferrin. Transferrin is internalized in $\mathrm{CHO}$ cells by receptor-mediated endocytosis and localizes to early and recycling endosomes (26). Fig. $3 F$ shows by confocal microscopy that rhodamine transferrin has a similar distribution to that of wild-type AQP2; the pericentriolar recycling endosome is labeled by both AQP2 antibody (left, $3 F$ ) and rhodamine transferrin (right, $3 F$ ). Fig. $3 G$ shows colocalization of an AQP2 mutant, T126M (left) and an ER resident protein (Grp94, right) (27) to a reticular compartment characteristic of the ER.

Further evaluation of the intracellular distribution of the AQP2 mutants was carried out by immunoblot analysis of membrane vesicles obtained after cell homogenization and membrane fractionation by sucrose density gradient centrifugation. Fig. $4 A$ shows membrane fractions blotted with a calnexin antibody (ER-localizing) (28) and an alkaline phosphatase antibody (endosome and plasma membrane-localizing) (29). The same amount of protein was loaded onto each lane. As predicted for this fractionation procedure, ER was localized mainly to fractions $2-4$, and endosomes and plasma membranes to fractions $6-8$. Fig. $4 \mathrm{~B}$ provides representative immunoblots of AQP2, showing localization of wild-type AQP2 mainly to fraction 8 . The L22V mutant was also detected in fraction 8 and was present to a lesser extent in fraction 3 . T126M, A147T, and R187C were localized mainly to fractions $2-4$. The ER fractions contained a $29-\mathrm{kD}$ band and an $\sim 31$ $\mathrm{kD}$ protein. The $31-\mathrm{kD}$ band, which was seen to a variable ex-
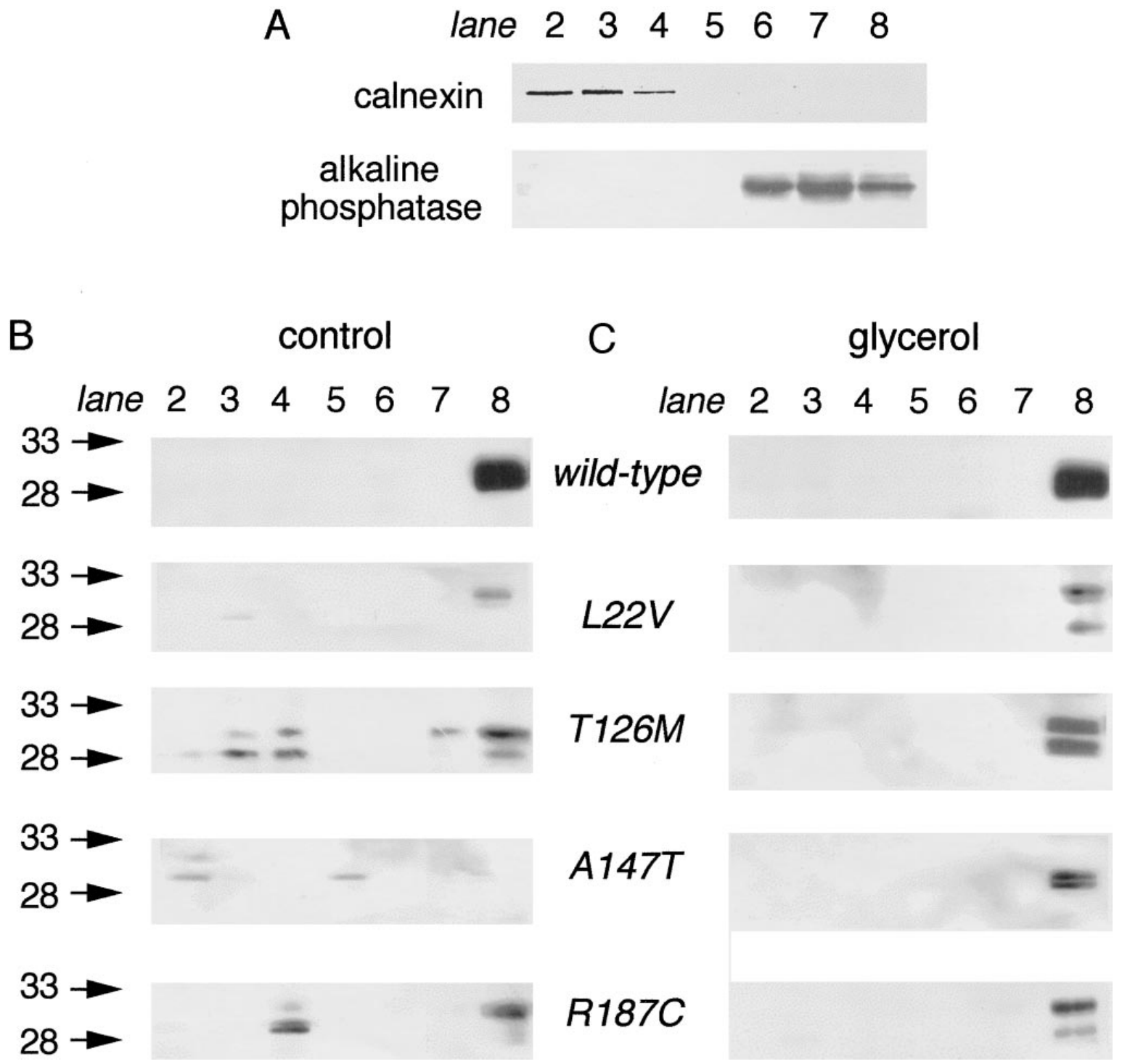

Figure 4. Immunoblot analysis of density gradient fractionated vesicles from AQP2-transfected cells. Membranes were fractionated by sucrose density gradient centrifugation as described in the Methods. Each lane was loaded with $2.5 \mu \mathrm{g}$ protein. $(A)$ Blots of fractionated membranes probed with antibodies against an ER marker (calnexin) and an endosome/plasma membrane marker (alkaline phosphatase). (B) Blots of cells transfected with wild-type AQP2 or indicated AQP2 mutants and probed by AQP2 antibody. $(C)$ Blots as in $B$, except that cells were grown in $1 \mathrm{M}$ glycerol for $40 \mathrm{~h}$ as described in Methods. Each blot represents one study typical of three. 
tent in different experiments, was insensitive to endoglycosidase-F and therefore probably represents a nonglycosylated form of AQP2 with altered migration on SDS-PAGE.

Because some AQP2 mutant proteins can be functional (Fig. 1) and relatively stable (Fig. 2), yet retained in the ER of mammalian cells (Figs. 3 and 4), we tested the hypothesis that agents that promote protein folding in vitro (30) and in vivo (14-17) might facilitate trafficking of NDI-causing AQP2 mutants. At $4 \mathrm{~h}$ after transfection, the chemical chaperone glycerol was added to the medium and cells were grown for an additional $40 \mathrm{~h}$. Cells were then processed for membrane fractionation, or fixed for immunostaining. For immunostaining, samples were graded as ER, plasma membrane/endosome, or a mixed distribution by an investigator who was blinded to sample identity and to whether glycerol had been present.

Fig. $4 C$ shows immunoblot analysis of cells grown in the presence of glycerol, a chemical chaperone that was found previously to correct defective protein processing of CFTR, and temperature-sensitive mutations of $\mathrm{p} 53$ tumor suppressor protein (16), and prevent conversion of prion protein to its scrapie form (17). Compared to cells grown without glycerol, there was a remarkable redistribution in the gradient localization for several AQP2 mutants. L22V, R187C, A147T, and T126M were detected in the endosome/plasma membrane fraction and not in the ER fraction. Glycerol did not alter the distribution of the ER marker calnexin (not shown). These results sug-
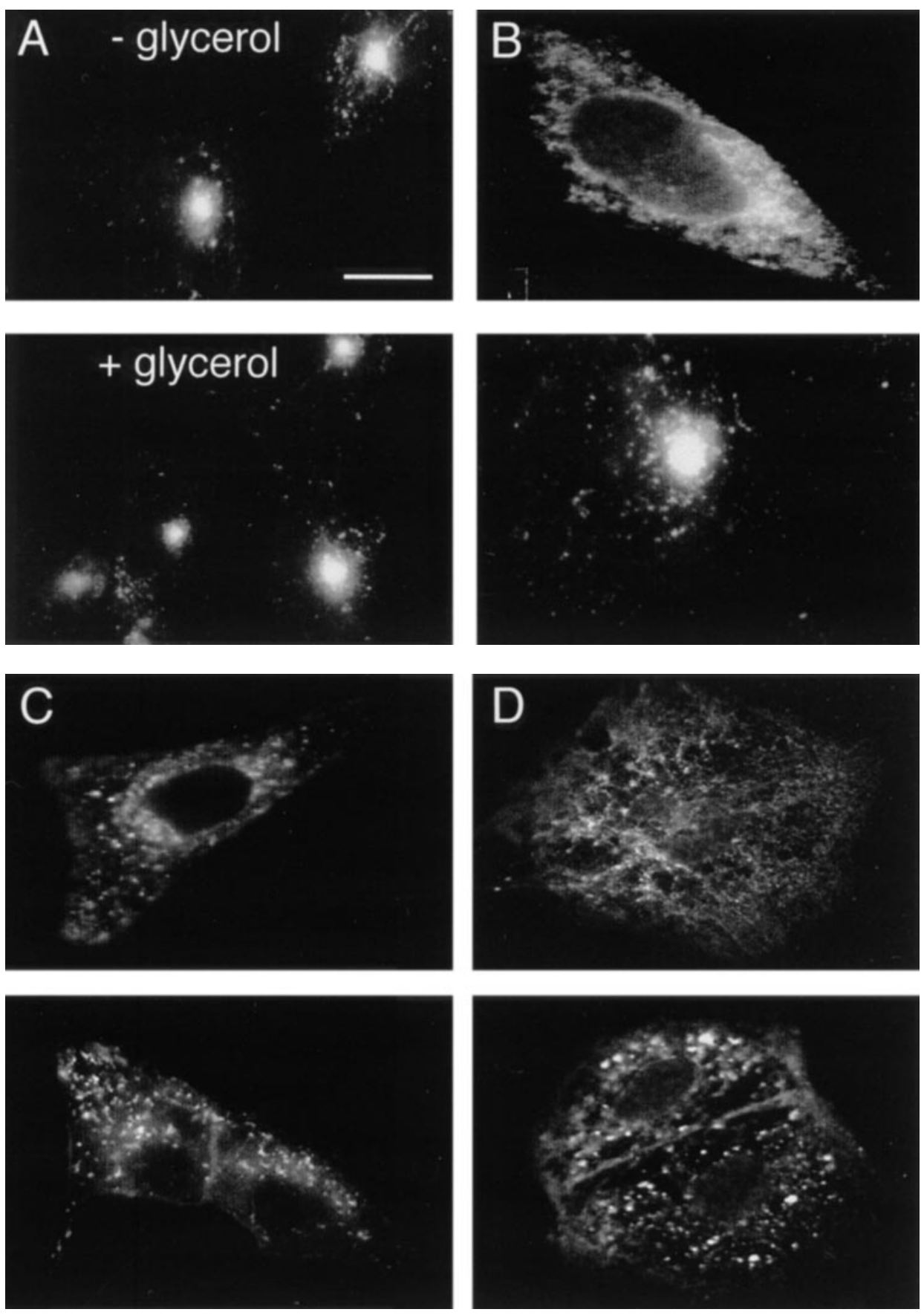

Figure 5. Influence of glycerol on cellular AQP2 distribution. Immunofluorescence localization of AQP2 in transiently transfected cells. Representative cells are shown from cultures grown in the absence (top) or the presence (bottom) of $1 \mathrm{M}$ glycerol. (A) $\mathrm{CHO}$ cells expressing wild-type AQP2. (B) CHO cells expressing A147T. (C) MDCK cells expressing wild-type AQP2. $(D)$ MDCK cells expressing T126M AQP2. 
gest that glycerol enables a greater percentage of mutant AQP2 protein to exit the ER and be transported to downstream compartments.

Immunostaining was done in glycerol-treated cells to quantify the redistribution of AQP2 on a cell-to-cell basis. Fig. 5 shows representative immunofluorescence micrographs of control (top) versus glycerol-treated (bottom) cells. Glycerol did not alter the staining pattern of wild-type AQP2 (Fig. $5 A$ ), which was distributed to endosomes and the plasma membrane. However, A147T redistributed from a reticular-staining pattern in control cells to an endosomal pattern with staining of discrete endosomes and the recycling endosome (Fig. $5 \mathrm{~B}$ ). There was also a redistribution of R187C, L22V, and T126M (not shown) from a reticular ER-staining pattern to a mixed vesicular-staining pattern with staining also of the pericentriolar recycling endosomal compartment (not shown). In
MDCK cells, wild-type AQP2 was localized to endosomes (Fig. $5 C$ ) and its distribution did not change with glycerol. In MDCK cells, T126M was seen in a reticular compartment that resembles the ER, and redistributed to an endosomal pattern after glycerol (Fig. $5 \mathrm{D}$ ). To determine if any of the AQP2 mutants are temperature sensitive, as found for $\triangle$ F508 CFTR (31), cells were incubated at 26 or $30^{\circ} \mathrm{C}$ for $36 \mathrm{~h}$. In contrast to results for CFTR, growing cells at low temperatures caused the accumulation of both the wild-type and AQP2 mutants in the ER.

Fig. $6 \mathrm{~A}$ summarizes the results of the blinded grading of AQP2 intracellular distribution. Although glycerol incubation produced little or no change in the distribution of wild-type AQP2, there was a significant decrease in the fraction of cells with ER staining pattern for L22V, T126M, A147T, and $\mathrm{R} 187 \mathrm{C}$. It is noted that even for cells expressing wild-type
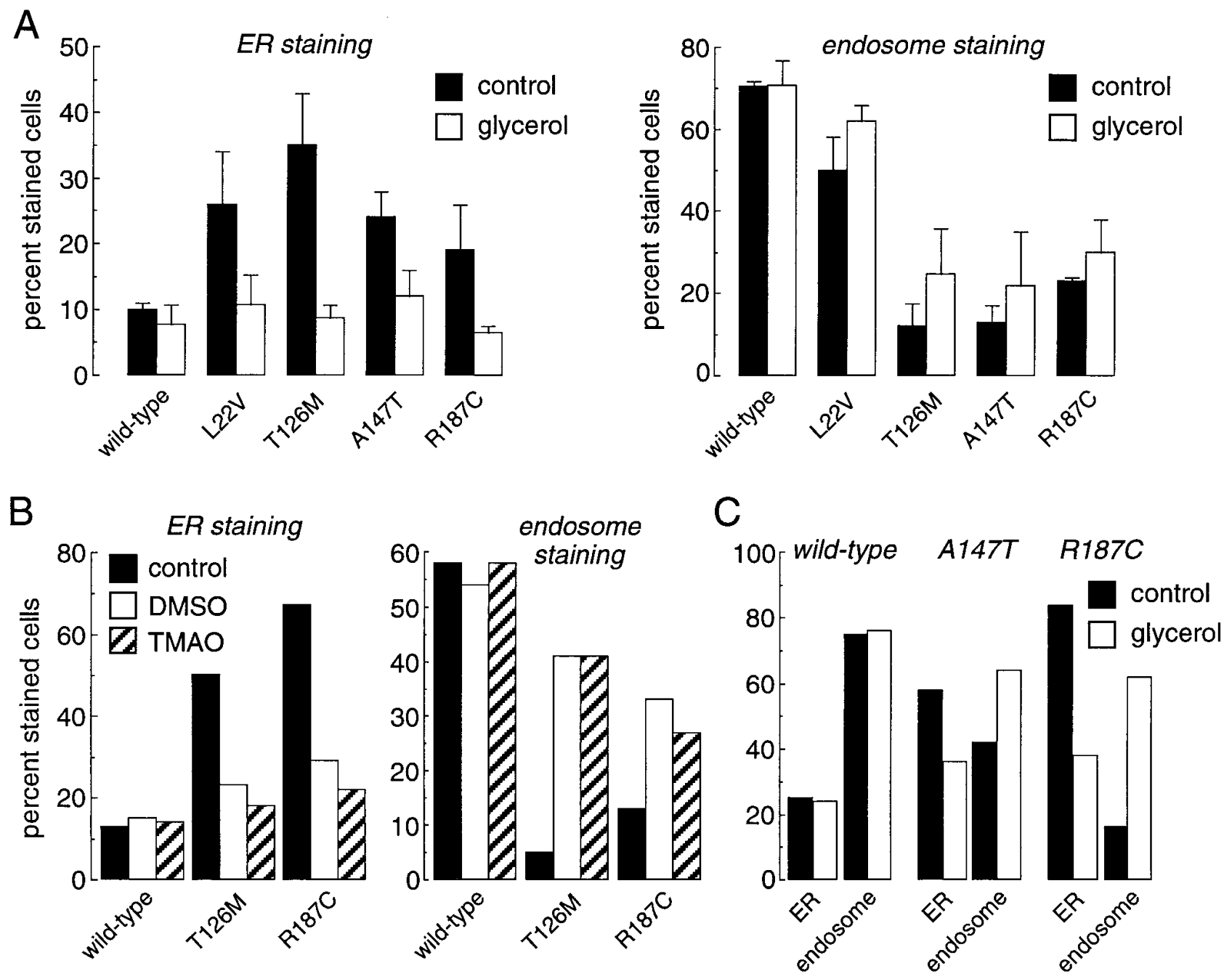

Figure 6. Grading of staining patterns in cells grown in the absence or presence of glycerol or other chemical chaperones. $(A)$ Cells were prepared as in Fig. 5, and the intracellular staining pattern was graded in a blinded fashion according to the pattern of immunoreactivity: reticular staining was defined as an ER distribution, and staining of early and recycling endosomes or plasma membrane was defined as endosome distribution. Each bar represents the mean \pm SEM of gradings done for $n=3-4$ separate sets of cultures, with generally $>75$ cells graded in each group for each condition. (B) Cells grown in the presence or absence of TMAO (100 mM) or DMSO (280 mM) were stained with AQP2 rabbit antibody and graded as in $A$. Each bar represents grading done for cultures with $>75$ cells in each group for each condition. (C) MDCK cells grown in the presence or the absence of glycerol $(1 \mathrm{M})$ were stained with c-Myc antibody and graded in a blinded fashion: reticular staining as ER and distinct endosomes as endosome. Each bar represents grading done for cultures with $>75$ cells in each group for each condition. 
AQP2, there was a small fraction of cells with an apparent ER protein distribution. Incubation in glycerol reduced the fraction of cells with an ER-staining pattern for L22V, T126M, A147T, and R187C to levels similar to wild-type AQP2. This dramatic reduction in the ER retention of AQP2 would account for the absence of AQP2 in the ER containing fractions in the immunoblot analysis (Fig. 4 B).

To examine whether glycerol functions as a chemical chaperone for correction of mutant AQP2 trafficking, several compounds that have been proposed to act as chemical chaperones (32) were tested. Fig. $6 \mathrm{~B}$ indicates that TMAO and DMSO were effective in correcting the ER retention of AQP2 mutants. Importantly, correction was achieved at much lower concentrations than that required for glycerol: TMAO $(100 \mathrm{mM})$ and DMSO $(280 \mathrm{mM})$. Fig. $6 C$ shows that glycerol can correct mutant AQP2 trafficking in MDCK cells, a renal epithelial cell line.

The transfection efficiency in the absence versus the presence of glycerol was measured to determine if the glycerolinduced decrease of cells with ER staining is related to the selective loss of cells expressing AQP2 mutants in the ER. The transfection efficiencies expressed as a percentage of the total number of cells were: wild-type (control) $65 \pm 1 \%$, wild-type (glycerol) 65 $\pm 3 \%$; L22V (control) 66 $\pm 5 \%$, L22V (glycerol) $64 \pm 6 \%$; A147T (control) 26 $\pm 7 \%$, A147T (glycerol) $24 \pm 3 \%$; T126M (control) $21 \pm 0 \%$, T126M (glycerol) $20 \pm 1 \%$; R187C (control) $27 \pm 4 \%, \mathrm{R} 187 \mathrm{C}$ (glycerol) $24 \pm 5 \%$. Glycerol treatment, thus, did not alter the transfection efficiency of wild-type or mutant AQP2 proteins.

Water permeability measurements were carried out to determine if glycerol treatment results in functional correction of the trafficking defect. A TIRF method was developed that permits water permeability measurements selectively in AQP2expressing cells using a transient transfection procedure (see Methods). Fig. $7 A$ shows the time course of TIR fluorescence (inversely proportional to cell volume) in response to osmotically induced cell swelling and shrinking. Experiments were done in $\mathrm{CHO}$ cells expressing the T126M AQP2 mutant, which is functional in oocytes but severely misrouted in $\mathrm{CHO}$ cells. Rates of cell swelling and shrinking were threefold higher in cells expressing wild-type AQP2 compared to control (average rates given in Fig. $7 \mathrm{~B}$ ). Water transport was significantly increased in glycerol-treated cells expressing AQP2T126M. Glycerol treatment did not affect water permeability in cells expressing wild-type AQP2.

\section{Discussion}

The first objective of this study was to determine whether the impaired water permeability associated with NDI-causing AQP2 mutations is due to decreased intrinsic AQP2 water permeability, accelerated AQP2 degradation, and/or AQP2 mistrafficking. Single-channel water permeabilities for wildtype AQP2, L22V, T126M, and A147T were similar when expressed in Xenopus oocytes, whereas R187C was nonfunctional; water permeability of $\mathrm{C} 181 \mathrm{~W}$ could not be measured because this protein was not targeted to the oocyte plasma membrane. In pulse-chase experiments in transfected $\mathrm{CHO}$ cells, the rates of degradation of AQP2 mutants A147T, R187C, C181W, and T126M were mildly accelerated when compared to wild-type AQP2. By immunocytochemistry and membrane fractionation, there were clear-cut differences in

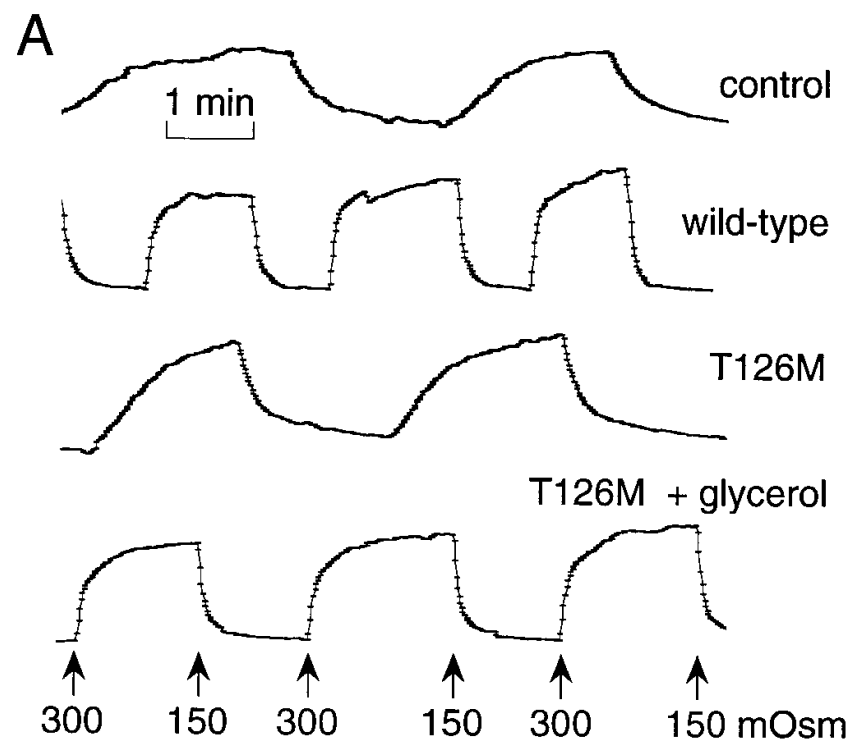

$\mathrm{B}$
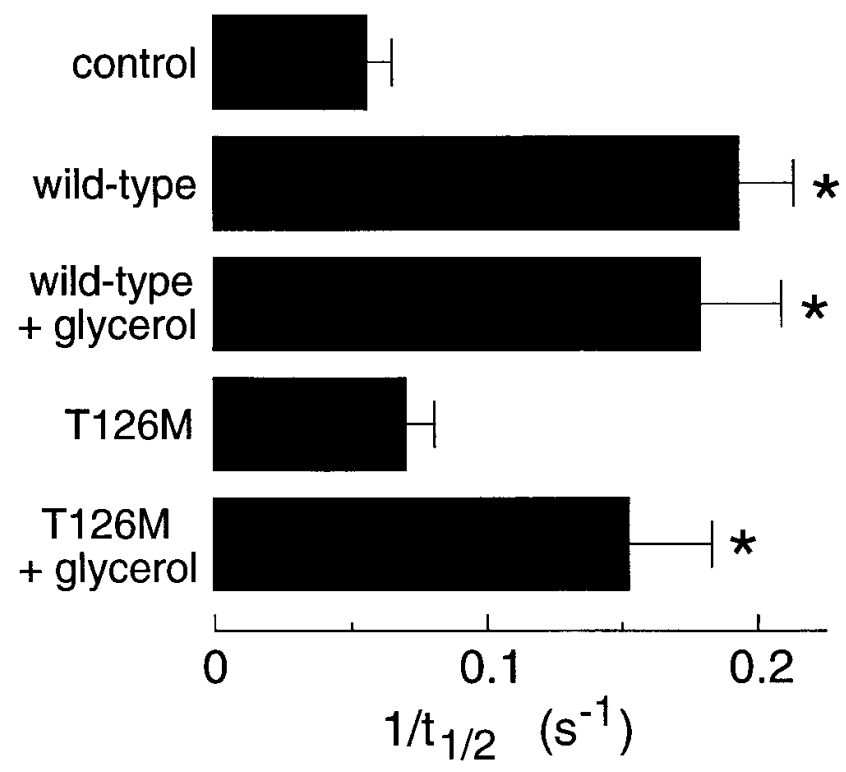

Figure 7. Functional analysis of glycerol-treated cells. $\mathrm{CHO}$ cells were transfected with cDNAs encoding wild-type AQP2 or AQP2T126M and GFP as described in Methods. Total internal reflection fluorescence was measured continuously during superfusion of cell layers with PBS (300 $\mathrm{mOsm}$ ) or PBS diluted 1:1 with water $(150 \mathrm{mOsm})$. (A) Time course of cell volume (inversely related to fluorescence signal) in response to fluid exchange for indicated cell transfections. $(B)$ Summary of apparent water transport rates (reciprocal half-times, $\left.1 / t_{1 / 2}\right)($ mean $\pm \mathrm{SE}, n=6) .{ }^{*}, P<0.05$.

the intracellular localization of the mutant AQP2 proteins with different degrees of ER retention. A second objective of the study was to develop a pharmacological strategy to correct the NDI-causing AQP2 defect. Based on the conclusion that trafficking of AQP2 mutants is a primary defect, we tested the hypothesis that protein-folding enhancers, or chemical chaperones, could correct defective AQP2 trafficking. These agents were shown by immunoblot analysis and immunocytochemis- 
try to cause a marked redistribution of AQP2 mutants from the ER to a downstream membrane compartment with increased cellular water permeability.

Newly synthesized proteins in the secretory pathway undergo posttranslational modification, folding, and oligomerization in the ER. This quality control in the ER is orchestrated by molecular chaperones, some of which include calnexin, calreticulin, PDI, Bip, and Grp94 (33). There is evidence for the interaction of membrane receptors and transporters with calnexin, Bip, and Hsp70 during their oligomeric assembly or folding in the ER. Misfolded or unassembled proteins are often retained in the ER and targeted for degradation (34), examples of which include the $\Delta$ F508 CFTR mutant, the truncated $\alpha$ chain of $\beta$-hexosaminidase, and unassembled subunits of the $\mathrm{T}$ cell receptor $(34,35)$. The accumulation of T126M, A147T, R187C AQP2 mutants in the ER suggests that mistrafficking of these proteins may result from defective folding or assembly in the ER. The mildly accelerated degradation of these proteins is consistent with targeting of these misfolded proteins for ER-dependent degradation. A prolonged association of $\Delta$ F508 CFTR mutant with Hsp70 and calnexin has been reported and is thought to serve as a signaling mechanism for subsequent degradation $(36,37)$. Similar interactions might occur for the AQP2 mutants.

Chemical chaperones have been shown in cell culture models to correct protein processing defects associated with several temperature-sensitive mutations including the $\Delta$ F508 CFTR $(14,15)$, p53 tumor suppressor protein, transforming protein encoded by Rous sarcoma virus, and temperature-sensitive mutations of E1 enzyme in the ubiquitination pathway (16). In cystic fibrosis, exposure of cells to $0.5-1 \mathrm{M}$ glycerol resulted in biochemical and functional correction of the $\Delta$ F508 CFTRtrafficking defect $(14,15)$. Glycerol and related chemical chaperones have been shown to stabilize proteins in vitro and reduce their aggregation in response to thermal stress $(30,38,39)$. Other proposed mechanisms include the lowering of a ratelimiting energy barrier in the folding pathway of newly synthesized proteins, and a decreased rate of formation of off-pathway conformers (40). It has been suggested that glycerol may inhibit the rate of protein synthesis and processing, enabling newly synthesized proteins to fold properly (14). Chemical chaperones may also have direct effects on protein interactions with molecular chaperones such as Hsp70 and calnexin (14).

The ability of glycerol to promote translocation of AQP2 mutants from ER to an endosomal/membrane compartment suggests a pharmacological strategy for in vivo correction of defective AQP2 processing in NDI. Although glycerol concentrations of $>0.5 \mathrm{M}$ cannot be obtained in mammals, the fish osmolyte TMAO can be maintained at concentrations of 50$75 \mathrm{mM}$ in mice with minimal toxicity (41). TMAO was found to be concentrated in urine 10 -fold over that in serum, suggesting that high intracellular TMAO concentrations may be obtainable in renal medulla. TMAO or more potent chemical chaperones might provide a clinically useful tool to correct the AQP2 protein-folding defect in NDI.

In summary, the principal problem in many NDI-causing mutations of the AQP2 water channel is defective protein processing and ER retention. Based on the analysis of defective trafficking of CFTR and other proteins, it is likely that the paradigms elucidated here for defective AQP2 trafficking and correction by chemical chaperones also apply in vivo. An important next step will be the analysis and correction of defec- tive trafficking of NDI-causing AQP2 mutants in transgenic mouse models of NDI.

\section{Acknowledgments}

We thank William Welch for helpful discussions.

This work was supported by grant DK35124 and HL59198 from the National Institutes of Health (Bethesda, MD). B.K. Tamarappoo was supported by NRSA award DK09484.

\section{References}

1. Fujiwara, T.M., K. Morgan, and D.G. Bichet. 1995. Molecular biology of diabetes insipidus. Ann. Rev. Med. 46:331-343.

2. Pan, Y., A. Metzenberg, S. Das, B. Jing, and J. Gitscher. 1992. Mutations in the V2 vasopressin receptor gene associated with X-linked nephrogenic diabetes insipidus. Nat. Genet. 2:103-106.

3. van Lieburg, A.F., M.A. Verdijk, V.V.A.M. Knoers, A.J. van Essen, W. Proesmans, R. Mallman, L.A. Monnens, B.A. van Oost, C.H. van Os, and P.M Deen. 1994. Patients with autosomal nephrogenic diabetes insipidus: homozygous for mutations in the aquaporin 2 water channel gene. Am. J. Hum. Genet. 55:648-652.

4. Langley, J.M., J.W. Balfe, T. Selander, P.N. Ray, and J.T. Clarke. 1991. Autosomal recessive inheritance of vasopressin-resistant diabetes insipidus. Am. J. Med. Genet. 38:90-94.

5. Deen, P.M., M.A. Verdijk, N.V.A.M. Knoers, B. Wieringa, L.A. Monnens, C.H. van Os, and B.A. van Oost. 1994. Requirement of human renal water channel aquaporin-2 for vasopressin-dependent concentration of urine. Science. 264:92-95.

6. Fushimi, K., S. Uchida, Y. Hara, Y. Hirata, F. Marumo, and S. Sasaki. 1993. Cloning and expression of apical membrane water channel of rat kidney collecting tubule. Nature. 361:549-552.

7. Brown, D. 1989. Membrane recycling and epithelial function. Am. J. Physiol. 26:F1-F12.

8. Nielsen, S., C.L. Chou, D. Marples, E.I. Christensen, B.K. Kishore, and M.A. Knepper. 1995. Vasopressin increases water permeability of kidney collecting duct by inducing translocation of aquaporin-CD water channels to the plasma membrane. Proc. Natl. Acad. Sci. USA. 92:1013-1017.

9. Sabolic, I., F. Wuarin, L.B. Shi, A.S. Verkman, D.A. Ausiello, S. Gluck, and D. Brown. 1992. Apical endosomes from collecting duct principal cells lack subunits of the proton pumping ATPase. J. Cell Biol. 119:111-122.

10. Deen, P.M., H.C. Remon, A.M.H. van Aubel, L.A. Ginsel, and C.H. van Os. 1995. Water channels encoded by mutant aquaporin-2 genes in nephrogenic diabetes insipidus are impaired in their cellular routing. J. Clin. Invest. 95: 2291-2296.

11. Mulders, S.H., N.V.A.M. Knoers, A.F. van Lieburg, L.A. Monnens, E. Leumann, E. Wuhl, E. Schober, J.P. Rijss, C.H. van Os, and P.M. Deen. 1997. New mutations in the AQP2 gene in nephrogenic diabetes insipidus resulting in functional but misrouted water channels. J. Am. Soc. Nephrol. 8:242-248.

12. Canfield, M.C., B.K. Tamarappoo, A.M. Moses, A.S. Verkman, and E.J. Holtzman. 1997. Identification and characterization of aquaporin-2 water channel mutations causing nephrogenic diabetes insipidus with partial vasopressin response. Hum. Mol. Genet. 6:1865-1871.

13. Welsh, M.J., and A.E. Smith. 1993. Molecular mechanisms of CFTR chloride channel dysfunction in cystic fibrosis. Cell. 73:1251-1254.

14. Brown, C.R., L.Q. Hong-Brown, J. Biwersi, A.S. Verkman, and W.J. Welch. 1996. Chemical chaperones correct the mutant phenotype of the $\Delta$ F508 cystic fibrosis transmembrane conductance regulator protein. Cell Stress Chaperones. 1:117-125.

15. Sato, S., C.L. Ward, M.E. Krouse, J.J. Wine, and R.R. Kopito. 1996 Glycerol reverses the misfolding phenotype of the most common cystic fibrosis mutation. J. Biol. Chem. 271:635-638.

16. Brown, C.R., L.Q. Hong-Brown, and W.J. Welch. 1997. Correcting temperature-sensitive protein folding defects. J. Clin. Invest. 99:1432-1444.

17. Tatzelt, J., S.B. Prusiner, and W.J. Welch. 1996. Chemical chaperones interfere with the formation of scrapie prion protein. EMBO (Eur. Mol. Biol. Organ.) J. 15:6363-6373.

18. Sasaki, S., H. Saito, F. Saito, K. Fushimi, S. Uchida, Y. Rai, T. Ikeuchi, K. Inui, and F. Marumo. 1993. Cloning, expression and chromosomal mapping of human collecting duct water channel (hWCH-CD). J. Am. Soc. Nephrol. 4: 858-862.

19. Zhang, R., W. Skach, H. Hasegawa, A.N. van Hoek, and A.S. Verkman. 1993. Cloning, function and cellular localization of a proximal tubule water transporter homologous to CHIP28. J. Cell Biol. 120:359-369.

20. Evan, G.I., G.K. Lewis, G. Ramsay, and J.M. Bishop. 1985. Mol. Cell. Biol. 5:3610-3616.

21. Wall, D.A., and S. Patel. 1989. Isolation of plasma membrane complexes from Xenopus oocytes. J. Membr. Biol. 107:189-201.

22. Balch, W.E., W.G. Dunphy, W.A. Braell, and J.E. Rothman. 1984. Re- 
constitution of the transport of protein between successive compartments of the Golgi measured by the coupled incorporation of N-acetylglucosamine. Cell. 39: 405-416.

23. Farinas, J., V. Simanek, and A.S. Verkman. 1995. Cell volume measured in adherent cells by total internal reflection microfluorimetry: application to permeability in cells transfected with water channel homologs. Biophys. J. 68: 1613-1620.

24. Kornfeld, R., and S. Kornfeld. 1985. Assembly of asparagine-linked oligosaccharides. Annu. Rev. Biochem. 54:631-664.

25. Jung, J.S., G.M. Preston, B.L. Smith, W.B. Guggino, and P. Agre. 1994. Molecular structure of the water channel through aquaporin CHIP. The hour glass model. J. Biol. Chem. 269:14648-14654.

26. Marsh, E.W., P.L. Leopold, N.L. Jones, and F.R. Maxfield. 1995. Oligomerized transferrin receptors are selectively retained by a lumenal sorting signal in a long-lived endocytic recycling compartment. J. Cell Biol. 129:15091522 .

27. Melnick, J., S. Aviel, and Y. Argon. 1992. The endoplasmic reticulum stress protein GRP94, in addition to $\mathrm{BiP}$, associates with unassembled immunoglobulin chains. J. Biol. Chem. 267:21303-21306.

28. Bergeron, J.J.M., M.B. Brenner, D.Y. Thomas, and D.B. Williams. 1994. Calnexin: a membrane-bound chaperone of the endoplasmic reticulum. Trends Biochem. Sci. 19:124-128.

29. Storrie, B., and E.A. Madden. 1990. Isolation of subcellular organelles. Methods Enzymol. 182:203-205.

30. Gekko, K., and S.N. Timasheff. 1981. Mechanisms of protein stabilization by glycerol: preferential hydration in glycerol-water mixtures. Biochemistry. 20:4677-4686.

31. Denning, G.M., M.P. Anderson, J.F. Amara, J. Marshall, A.E. Smith, and M.J. Welsh. 1992. Processing of mutant cystic fibrosis transmembrane con- ductance regulator is temperature-sensitive. Nature. 358:761-764.

32. Welch, W.J., and C.R. Brown. 1996. Influence of molecular and chemical chaperones on protein folding. Cell Stress Chaperones. 1:109-115.

33. Hammond, C., and A. Helenius. 1995. Quality control in the secretory pathway. Curr. Opin. Cell Biol. 3:592-600.

34. Bonifacino, J.S., and S.J. Lippincot. 1991. Degradation of proteins within the endoplasmic reticulum. Curr. Opin. Cell Biol. 7:592-600.

35. Ward, C.L., and R.R. Kopito. 1995. Degradation of CFTR by the ubiquitin-proteasome pathway. Cell. 83:121-127.

36. Yang, Y., S. Janich, J.A. Cohn, and J.M. Wilson. 1993. The common variant of cystic fibrosis transmembrane conductance regulator is recognized by hsp70 and degraded in a pre-Golgi non-lysosomal compartment. Proc. Natl. Acad. Sci. USA. 90:9480-9484.

37. Pind, S., J.R. Riordan, and D.B. Williams. 1994. Participation of the endoplasmic reticulum chaperone calnexin (p88, IP 90) in the biogenesis of the cystic fibrosis transmembrane conductance regulator. J. Biol. Chem. 269:1278412788.

38. Gekko, K., and S. Koga. 1983. Increased thermostability of collagen in the presence of sugars and polyols. J. Biochem. 94:199-208.

39. Edington, B.V., S.A. Whelan, and L.E. Hightower. 1989. Inhibition of heat shock (stress) protein induction by deuterium oxide and glycerol: Additional support for the abnormal protein hypothesis of induction. J. Cell. Physiol. 139:219-228.

40. Qu, B.H., E.H. Strickland, and P.J. Thomas. 1997. Localization and supression of a kinetic defect in cystic fibrosis transmembrane conductance regulator folding. J. Biol. Chem. 272:15739-15744.

41. Bai, C., J. Biwersi, R. Brown, A.S. Verkman, and M.A. Matthay. 1997. An in vivo model to test the efficacy of chemical chaperones for correction of the $\Delta$ F508 CFTR trafficking defect. Pediatr. Pulmon. 14:271. 